\title{
Caregivers' Question Use and the Contributions of Children with Vocabulary Delay and Typically Developing Children During Shared Book-Reading
}

\author{
Sangeon Lee, Dongsun Yim \\ Department of Communication Disorders, Ewha Womans University, Seoul, Korea
}

Correspondence: Dongsun Yim, PhD Department of Communication Disorders, Ewha Womans University, 52 Ewhayeodae-gil, Seodamun-gu, Seoul 03760, Korea

Tel: $+82-2-3277-6720$

Fax: $+82-2-3277-2122$

E-mail: sunyim@ewha.ac.kr

Received: July 5, 2018

Revised: August 1, 2018

Accepted: August 14, 2018

This work was supported by the National Research Foundation of Korea Grant funded by the Korean Government (NRF-2016R1D1A1B03935703).

\begin{abstract}
Objectives: The linguistic interaction between parents and children during book reading is an important factor in the child's language and literacy development. Therefore, we investigated the relationship between cognitively different caregivers' question types and the contributions of vocabulary delayed children. Methods: Participants consisted of 17 children with vocabulary delay (VD group), aged 4 to 6 , their mothers, and 17 pairs of agematched typically developing children (TD group) and their mothers. In order to analyze the relationship between the maternal question and the child's response, the situation of reading and asking questions about two books to the child was recorded. Results: The correct response rate to the different types of questions was higher in the TD group than that of the VD group. The rate of the referential question following by the rate of the child's referential correct response and inferential question rate according to the child's inferential incorrect response were significantly higher in VD group than those of TD group. The ratio of the inferential questions following by child's referential correct responses and the rate of the referential questions to the child's inferential incorrect contributions was fundamentally higher in the TD group than that of the VD group. Conclusion: The caregiver and child may have a linguistic impact on each other during book reading. This is clinically related to various types of caregiver questions. Different cognitive levels of maternal question use, based on the child's age, language, and cognitive level, can be recommended in caregiver book-reading training.
\end{abstract}

Keywords: Children with vocabulary delay, Caregiver-child book reading interaction, Maternal referential question, Maternal inferential question
많은 아동들은 어린 시기에 성인으로부터 책에 대해 탐색할 수 있는 기회를 많이 얻도록 권장되며, 이러한 조기 경험은 아동과 성 인이 함께 하는 상호작용적 책읽기를 이끌어 낸다(Karrass \& Braungart-Rieker, 2005). 비록 학령기 문해발달에 영향을 미치는 초기 언 어발달 시기에 상호작용적 책읽기 조기 중재의 효과에 대한 연구 에서 서로 다른 견해가 있지만(Scarborough \& Dobrich, 1994), 양 육자-아동 상호작용적 책읽기는 학령전기 아동의 언어와 초기 문 해력 발달에 아주 중요한 역할을 한다고 하였다(Adams, 1990; Bus, Van Ijzendoorn, \& Pellegrini, 1995; Bus, Belsky, Van Ijzendoom, \& Crnic, 1997; Crain-Thoreson \& Dale, 1992; Hindman, Wasik, \&
Erhart, 2012; Justice \& Kaderavck, 2002; Lonigan, 1994; Snow, Burns, \& Griffin, 1998; Whitehurst et al., 1988). 또한 상호작용적 책읽기의 중요한 특징 중 한 가지는 아동에게 탈맥락적 언어와 어 휘를 학습할 수 있는 기회를 함께 제공한다(Dickinson \& Snow, 1987; Snow, 1983). 여기서 언급하는 탈맥락적 언어는 어떠한 정보 에 대한 맥락적 이해가 적은 청자에게 새로운 정보를 전달하는 언 어를 의미하며 아동의 해독 능력, 이야기 내용에 대한 이해, 이야기 표현과 같은 일반적인 문해 능력의 요소와 밀접한 관계가 있다 (Dickinson \& Snow, 1987). 그뿐만 아니라 아동은 책읽기를 통해 일상 대화에서 유용하지 않은 어휘를 배우기도 하지만 인쇄물에 
대한 정보는 물론 언어의 구조에 대해서도 배울 수 있으며, 구문발 달에 긍정적 영향을 준다(Han, Seong, \& Choi, 2016). 마찬가지로, Kang과 Hong (2016)의 연구에서 상호작용적 책읽기를 통해 만 6-7 세 단순언어장애 아동의 거시적, 미시적 이야기 재구성 능력에 큰 영향을 주었음을 밝혔다. 책을 읽는 동안 양육자는 아동에게 더욱 정교한 언어 자극을 제공하며 아동이 함께 참여할 수 있는 기회를 부여한다(Arnold, Lonigan, Whitehurst, \& Epstein, 1994; Bus, 2003; Girolametto, Weitzman, \& Greenberg, 2003). 또한 양육자는 책읽기 시 아동에게 새로운 어휘들을 노출시켜주기도 하고, 아동 의 말에 대해 반복하고 확장하거나 수정하기도 하면서 인지적으로 높은수준의 대화를 가능하게 한다(Massey, Pence, Justice, \& Bowles, 2008; Montag, Jones, \& Smith, 2015; Oh, Kim, \& Lee, 2008). 반대 로, 아동측면에서 살펴보았을 때 양육자와의 책읽기 시 책에 나타 난 그림의 상황이나 이름을 산출하며 활발하게 참여한 아동이 수 동적으로 참여한 아동보다 더 많은 어휘를 습득하였음을 밝혔다 (Sénéchal, Thomas, \& Monker, 1995; Oh et al., 2008). 이와 비슷한 Sénéchal, LeFevre, Hudson과 Lawson (1996)의 연구에서 아동의 이야기책에 대한 지식습득은 아동의 수용 및 표현어휘 수준에 따 라 다르다고 제시하였다. 이처럼 책읽기는 양육자와 아동이 적극적 으로 참여함으로써 질적으로 풍부한 언어 경험을 할 수 있는 역동 적 과정이라고 볼 수 있으며(Rabidoux \& MacDonald, 2000), 물론 교사의 도움도 중요하지만 가정에서의 도움이 더 중요하다고 언급 하였다(Clark, 1995; Cochran-Smith, 1984; Mandel Morow, 1983;

Pae, Kwon, Jin, Jun, \& Kwak, 2010; Yim, Cheon, Lee, \& Jeong, 2015). 이러한 선행연구 결과들은 양육자-아동 책읽기가 아동의 언어발 달에 긍정적 영향을 미칠 뿐 아니라, 책읽기 시 양육자와 아동의 상 호작용적 역할의 중요성도 함께 언급하고 있다.

양육자-아동 상호작용의 한 형태인 양육자의 반응은 아동의 언 어 학습에 도움이 되며, 이는 '정확한, 대표적인, 적절한' 육아로 묘 사되기도 한다(Bornstein \& Tamis-LeMonda, 1989). 또한, 양육자 가 아동에게 보다 적극적으로 반응을 해준다면 아동의 참여도를 높일 뿐 아니라(Owens, 2010) 이는 후에 아동의 언어발달을 예측할 수 있음을 제시하였다(Wheeler, Hatton, Reichardt, \& Bailey, 2007; Yoder \& Warren, 1999). 마찬가지로 책을 읽는 동안 나타나는 양육 자의 질문, 언급하기, 모방, 격려하기와 같은 행동은 아동의 수용 및 표현언어 발달을 촉진한다(Bus et al., 1997; Justice \& Kaderavck, 2002; Whitehurst et al., 1988). 그 중 양육자의 질문은 아동의 주의 를 환기시키는 역할을 한다. 양육자 질문은 코멘트와 달리 아동이 구어적 상호작용에 참여할 수 있도록 명시적으로 유도하는 역할을 하며, 아동은 질문을 통해 양육자와의 확장된 담화를 잠재적으로
경험할 수 있다. 많은 연구자들은 이러한 양육자의 질문이 아동 언 어발달을 증진시킬 수 있는지에 초점을 두고 있으며(Zucker, Cabell, Justice, Pentimonti, \& Kaderavek, 2013) 실제로 책읽기 시 양육 자의 질문은 질적으로 높은 책읽기 환경을 만들어주며 잦은 질문 은 아동의 언어, 서술 능력과 학교에서의 읽기 발달을 향상시켜줄 수 있다고 밝혔다(Melzi, Schick, \& Kennedy, 2011; Reese \& Newcombe, 2007). 양육자-학령전기 아동 책읽기 시 양육자의 질문이 아동에게 더 길고, 복잡하며 다양한 단어로 이루어진 발화를 이끌 어낸다(de Rivera et al., 2005). 마찬가지로 Sénéchal 등(1995)의 연 구에서 만 4 세 일반아동의 상호작용적 책읽기 시 나타나는 양육자 의 질문은 중요한 역할을 한다고 제시하였다. 이처럼 여러 연구에서 책읽기 시 출현하는 양육자 질문의 중요성에 대해 밝히고 있다.

사실적, 추론적 언어 능력(referential, inferential language ability)은 상대방과의 상호작용이나 책의 문맥 활동 내에서 보이는 아 동의 언어 능력에 근거하여 요구되는 인지수준에 따라 차이가 있다 (Chapman, 2000). 낮은 인지수준을 요구하는 사실질문은 아동이 어떠한 사물이나 등장인물에 대해 명명하거나 묘사할 수 있도록 한다. 예를 들면 이야기 책에 등장하는 사람이나 사물에 대한 질문 으로 ‘누가 달나라로 갔어?', ‘달곰이가 뭐 먹었어?'가 될 수 있다. 이 러한 질문은 아동이 이야기 흐름을 따라가는 데 도움을 주며, 아동 의 어휘발달을 촉진시킬 수 있지만 아동이 대답을 하기 위한 높은 인지적 수준을 요구하지는 않는다(Blank, Rose, \& Berlin, 1978). 실 제 책읽기 시 학령전기 아동의 $80 \%$ 는 사실적 이해와 관련된 내용 에 초점을 두고 있는 것으로 밝혀졌다(Danis, Bernard, \& Leproux, 2000). 추론적 이해 능력은 아동이 자신의 경험에 대해 언급하거나 어떠한 사건에 대해 추론하거나 예측할 수 있게 하며, 사실적 이해 능력보다 더 높은 인지수준을 요구한다(Massey et al., 2008). 이러 한 추론적 언어 능력은 정상발달아동뿐만 아니라 언어발달에 어 려움을 보이는 아동들에서도 중요하다(Norbury \& Bishop, 2002). Van Kleeck, Vander Woude와 Hammett (2006)에 따르면, 추론 능 력은 아동이 읽기 위해 배우는 단계에서 배우기 위해 읽는 단계로 넘어감에 따라 즉, 아동의 연령이 증가함에 따라 학교에서의 학습 시에 중요한 역할을 하게 된다(Chall, 1983). 이렇게 높은 인지적 수 준을 요구하는 추론질문은 아동의 이해 능력을 향상시켜주어 더 성숙한 읽기 학습자로 거듭날 수 있게 하며(Palinscar \& Brown, 1984; Van Kleeck et al., 2006), 아동의 어휘와 인지발달에 매우 긍 정적이고 중요한 예측요인이 될 수 있음을 밝힌 바 있다(de Rivera et al., 2005; Dickinson \& Porche, 2011; Hindman \& Wasik, 2008; Lee \& Kinzie, 2012). 그러나 어떤 연구자들은 질문의 유형이 아동 의 반응을 이끌어내는 데 중요하지 않다고 밝혔으며(Walsh \& Ble- 
witt, 2006), 너무 어린 연령에 양육자의 추론적 질문유형에 노출된 다면 어려움이 따를 수 있기 때문에 아동 연령 수준에 맞는 질문을 제공하는 것이 중요하다고 강조한다(Danis et al., 2000; DeLoache \& DeMendoza, 1987; Pellegrini, Brody, \& Sigel, 1985; Sénéchal et al., 1995). 이러한 연구결과들을 바탕으로 양육자-아동 책읽기 시 아동의 인지 및 연령 수준에 적절하게 나타나는 양육자의 사실질문 과 추론질문이 아동의 언어발달에 미치는 중요성이 강조되고 있다.

양육자-아동의 상호작용적 책읽기 시 출현하는 양육자의 질문은 질적으로 높은 행동이라고 볼 수 있으며, 일반아동뿐 아니라 단순 언어장애 아동에게도 중요하다(Crain-Thoreson \& Dale, 1999; Whitehurst et al., 1988). 그러나 반대로 아동이 양육자의 질문에 미 치는 영향에 대한 연구는 부족한 실정이다. 다시 말해, 다양한 질문 에 대한 아동의 구어적 반응과 아동의 반응에 대한 양육자의 질문 을 살펴보아 책읽기 상황에서 나타나는 양육자-아동의 유기적인 상 호작용을 살펴보고자 한다. 실제로 책읽기 시 아동의 참여가 양육 자의 질문을 이끌어낼 것이고, 양육자의 질문이 아동의 참여를 이 끌어낼 수 있다. 이러한 점을 고려하여 이루어진 연구에서 양육자아동 책읽기 시 양육자의 질문유형과 그에 따른 아동의 구어 반응 의 관계는 인지수준에 의존함을 밝혔다(Danis et al., 2000; Lee \& Kinzie, 2012). 즉, 양육자의 질문의 인지적 수준에 따라아동의 반응 이 다르게 나타나며 서로 다르게 나타난 아동의 반응에 따라 나오 는 양육자의 질문의 인지적 수준도 달라지기 때문에 두 가지 요소의 상호작용이 중요하다. 이와비슷하게 양육자의 인지 및 언어 수준은 아동의 언어 능숙도와 관련이 있으며, 양육자는 아동의 구어 수행 력에 기초하여 인지적 요구 난이도를 조절함을 밝혔다(Pellegrini et al., 1985). 예를 들면, 아동의 대답이 틀렸을 때 양육자는 인지수준 이 더 낮은 질문을 이어서 할 수도 있으며, 반대로 아동이 정확하게 반응했을 때에는 더 높은 인지수준을 요구하는 질문으로 바꿀 수 도 있다. 따라서 책을 읽는 동안 나타난 양육자의 질문유형이 아동 의 반응에 어떻게 영향을 미쳤고, 반대로 아동의 반응이 양육자의 질문에는 어떠한 영향을 주는지 동시에 살펴볼 필요가 있다.

따라서 본 연구는 양육자-아동 책읽기 시 양육자의 사실 및 추 론질문에 대한 일반아동과 어휘발달지연 아동의 반응정확도에 대 해 살펴보고자 한다. 또한 아동의 반응정확도(정반응, 오반응) 및 반응유형(사실, 추론)에 따라 이어지는 양육자의 질문유형(사실, 추론)은 어떠한 패턴으로 상호작용하는지 살펴보고자 한다.

이에 따른 연구 질문은 다음과 같다.

첫째, 어휘발달지연 아동과 일반 아동 집단에서 양육자의 질문 유형(사실, 추론)에 따른 아동의 반응 정확도에서 유의한 차이가 나타나는가?
둘째, 사실, 추론 질문에 대한 아동의 반응 유형(정·오반응)에 따 른 양육자의 질문유형(사실, 추론)에서 집단 간 유의미한 차이가 나타나는가?

\section{연구방법}

\section{연구대상}

본 연구에 포함된 대상자는 서울, 경기, 부산 지역에 거주하는 생 활연령 4-6세의 어휘발달지연 아동 17명(평균연령 4;0-6;9, 여 8명, 남 9명), 그리고 이들과 생활연령을 일치시킨 일반아동 17 명(평균 연령 4;0-6;2, 여 10명, 남 7명), 양육자 34쌍(30대 27명, 40대 7명), 총 34 명을 대상으로 하였다.

본 연구에 참여한 어휘발달지연 아동은 다음과 같은 기준에 따 라 선정하였다. (1) 양육자나 교사에 의해 시각, 청각, 기타 신체 및 정서장애가 없다고 보고되었으며, (2) 수용-표현어휘력검사(Receptive \& Expressive Vocabulary Test, REVT; Kim, Hong, Kim, Jang, \& Lee, 2009) 결과, 수용 또는 표현어휘력이 - $1.25 \mathrm{SD}$ 미만이 며, (3) 카우프만 아동용 지능검사(Korean Kaufman Assessment Battery for Children, K-ABC; Moon \& Byun, 2003) 결과, 비언어성 지능지수가 85 점(-1 SD) 이상인 아동을 대상으로 하였다.

일반아동은 (1) 카우프만아동용지능검사(K-ABC; Moon \& Byun, 2003) 결과, 비언어성 지능 지수가 85점(-1 SD) 이상이며, (2) 수용·표현 어휘력검사(REVT; Kim et al., 2010) 결과, 수용어휘력과 표현어휘력 이 정상 범주(-1 SD 이상)인 아동으로서, (3) 양육자나 교사에 의해 시 각, 청각, 기타 신체 및 정서장애가 없다고 보고된 아동을 선정한다.

어휘발달지연 아동의 양육자 연령대는 30 대 14 명, 40 대 3 명으로 구성되었으며, 학력은 전문대 졸업 1 명, 대학교 졸업 15 명, 대학원 졸업 1 명으로 구성되었다. 일반아동의 양육자 연령대는 30 대 13 명, 40 대 4 명이며, 대학교 졸업 14 명, 대학원 졸업 3 명으로 구성되었다. 양육자 학력에 대한 기준은 $\operatorname{Kim}$ (2010)을 참고하여 분류하였다. 어 휘지연 및 일반아동 양육자는 (1) 모든 아동들의 양육자로, (2) 30-40 대 연령에 속하고, (3) 전문대 졸업 이상의 학력을 지니고 있으며, (4) 상호작용적 책읽기 시 나타난 양육자의 평균낱말길이(mean length of C-unit, MLC-w)에서 집단 간 차이가 없는 양육자로 선정 하였다.

본 연구에 참여한 아동과 양육자 기본정보는 Table 1 과 같다.

\section{연구과제}

양육자-아동 상호작용적 책읽기

책읽기는 따로 독립된 조용한 환경에서 이루어지며, 양육자가 아 
Table 1. Participants' characteristics

\begin{tabular}{lccc}
\hline & VD group & TD group & $p$-value \\
\hline $\begin{array}{l}\text { Children group } \\
\text { CA (mo) } \\
\text { REVT }\end{array}$ & $63.00 \pm 10.70$ & $60.18 \pm 10.25$ & .438 \\
$\quad$ & & \\
Receptive & $48.76 \pm 16.68$ & $69.41 \pm 14.88$ & $.001^{* *}$ \\
$\quad$ Expressive & $50.41 \pm 9.01$ & $72.53 \pm 9.44$ & $.001^{* *}$ \\
K-ABC & $113.24 \pm 14.21$ & $115.41 \pm 11.5$ & .627 \\
Mothers group & & & \\
CA (yr) & $37.06 \pm 2.33$ & $37.85 \pm 2.85$ & .367 \\
Period of education (yr) & $16 \pm .71$ & $16.30 \pm .73$ & .216 \\
MLC-w & $4.96 \pm .87$ & $4.92 \pm .87$ & .875 \\
\hline
\end{tabular}

Values are presented as mean $\pm S D$.

$\mathrm{VD}=$ vocabulary delay; $\mathrm{TD}=$ typically developing children; $\mathrm{CA}=$ chronological age; $\mathrm{MLC}=$ mean length of $\mathrm{C}$-unit; REVT = Receptive \& Expressive Vocabulary Test (Kim, Hong, Kim, Jang, \& Lee, 2009); K-ABC=Korean Kaufman Assessment Battery for Children (Moon \& Byun, 2003).

${ }^{* *} p<.01$.

동에게 총 2가지 책을 자연스럽게 읽어준다. 책읽기 시 선정된 책 2 권은 Hammett, Van Kleeck와 Huberty (2003) 연구에서 과제로 사 용된 “보름달케이크(Mooncake) (Asch, 1983)”와 “그림자가 따라 와요(Bear Shadow) (Asch, 1985)"이다. 이 책은 동일한 작가가 펴냈 으며, 영문판 Mooncake와 Bear Shadow의 번역본으로 우리나라 에서 2007년도에 절판되어 대부분의 양육자나 아동에게 내용에 대한 노출이 적을 것으로 예상되었다. 실제로 양육자를 대상으로 책 친숙도에 대한 물음을 하였을 때, 모든 대상 양육자는 두 권의 책을 본 적이 없다고 답하였다. 해당 책은 만 2-6세 아동을 대상으 로 하여 본 연구에 참여하는 만 4-6세 아동에게 읽어주기 적합하 다. 또한 두 권의 책은 동일한 페이지 수로 구성되어 있으며 본 연구 의 대상 아동이 이해하기 적절한 수준이다.

\section{자료수집}

본 연구에 참여한 대상자는 대부분 온라인카페 커뮤니티를 통 하여 모집되었으며, 연구자가 직접 가정에 방문하거나 기타 장소에 서 연구자료를 수집하였다.

한 아동당 2 회기 동안 선별 및 책읽기 검사를 진행하였다. 먼저 선별검사로 아동의 표현 및 수용어휘력을 측정하기 위한 REVT와 비언어성 인지능력을 살펴보기 위한 $\mathrm{K}-\mathrm{ABC}$ 를 실시하였다. 본 연 구는 조용한 공간에서 검사자와 아동은 책상에 앉아 독립적으로 진행되었으며, 검사 소요시간은 약 90 분 이내였다. 이어서 두 번째 회기 때 책읽기 검사를 시행하였으며, 소요시간은 50 분 이내로 이 루어졌다. 모든 책읽기 상황은 스마트폰으로 녹화되었으며 사전에 촬영동의서에 동의를 받고 진행하였다. 이야기책은 총 2 권으로 “보
름달케이크(Asch, 1983)"와 “그림자가 따라와요(Asch, 1985)" 순서 로 진행하였으며 책읽는 시간에 제한을 두지 않았다. 연구자는 양 육자에게 책을 제시하고 내용에 대해 먼저 살펴보게 한 후 책읽는 방법에 대해 특정한 지시사항 없이 아동에게 자연스럽게 읽어줄 것 을 요구하였다. 책을 다 읽은 후 연구자는 양육자에게 방금 읽었던 책 내용에 대해 아동에게 최대한 많은 질문을 해달라고 요구하였 다. 첫 번째 책읽기 상황 종료 후 10 분 동안 놀이 및 휴식을 하였다. 이어서 두 번째 책읽기를 시작하였으며 위와 동일한 방법으로 진행 되었다. 모든 검사가 완료된 후 연구자는 1-2주 이내로 선별검사 결 과에 대해 양육자가 이해하기 쉽도록 설명된 보고서를 제공하였으 며 아동과 양육자 간 상호작용 시 주의해야 할 의사소통법에 대한 안내를 간단히 한 후 본 연구의 자료수집을 마쳤다.

\section{자료분석}

본 과제의 자료수집 결과분석은 연구자가 녹화된 양육자-아동 책읽기 영상을 듣고 양육자와 아동의 발화를 전사하여 분석하였 다. 분석 시 필요한 모든 종속변인은 2 권의 책(보름달케이크, 그림 자가 따라와요)을 읽고 질문하는 시간 동안 산출되는 해당 발화에 각 1 점씩 부여하여 각 빈도수를 구한 후 비율점수로 환산하는 방식 을 적용하였다. 연구자는 질문만 따로 하는 상황뿐 아니라 자연스 럽게 책을 읽어주면서 중간에 나오는 질문 및 반응이 있었을 경우 분석에 포함시켰다. 분석시간은 두 가지 상황(질문만 하는 상황, 자 연스럽게 읽는 상황)이 포함된 영상을 15 분씩 끊어 발화분석을 하 였으며, 두 권의 책 모두 동일한 방법을 적용시켰다. 이때 책읽기 전 과 후 상황에서 책 내용과 관련 없는 부분의 영상은 제외시켰다. 양 육자의 발화 범위는 이야기책 텍스트를 읽는 발화와 책 내용과 관 련 없는 발화를 제외한 모든 발화를 말하며, 아동발화 또한 책읽기 상황 또는 내용과 관계없는 발화를 제외한 나머지 발화를 의미한 다. 양육자 및 아동 발화에 대한 정의는 선행연구(Luo \& Tamis-LeMonda, 2017)를 참고하여 분류하였으며 다음과 같다.

(1) 양육자의 사실질문은 책에 나오는 요소들의 이름, 묘사, 위치, 행동에 대한 질문으로 정의한다(예시: 책에 누가 나왔어? 달 곰이가 뮈하고 있어? 우주선이 무슨 색이야?)

(2) 양육자의 추론질문은 추론, 상상, 독백, 사회적 지식에 대한 질 문으로 정의한다(예시: 다음에 무슨 일이 일어날까? 달곰이는 어떤 기분이 들었을까? 왜 우주선에 갔을까? 우주선이 뮈야?)

(3) 아동의 사실적 반응은 그림에 제시된 요소의 이름, 특징, 위 치, 행동에 대한 언급으로 정의한다(예시: 이건 보름달케이크 야. 우주선은 빨간색이야. 달곰이가 그림자 뒤에 숨었어.)

(4) 아동의 추론적 반응은 추론, 상상, 독백, 사회적 지식에 대한 
언급으로 정의한다(예시: 달곰이는 슬펐어. 그림자를 없애려 고 도망갈 거야. 달케이크가 먹고 싶어서 우주에 갔어.)

분석 요인은 크게 두 가지로 나뉜다. (1) 양육자가 아동에게 한 책 내용과 관련된 질문(사실, 추론)에 대한 아동이 구어로 나타낸 반 응정확도이다. (2) 아동 반응의 정확도(정반응, 오반응) 및 유형(사 실, 추론)에 따라 이어서 나오는 양육자 질문(사실, 추론)은 어떠한 유형으로 나타나는지 반대로 살펴보고자 하였다. 이때, 아동 반응 (대답)은 먼저 정확도(정반응, 오반응)에 따라 분류한 후 어떠한 질 문유형(사실, 추론)에 따라 나타났는지 분석하였다. 즉, 아동 반응 (사실, 추론질문에 대한 정·오반응) 이후 연결되는 양육자 질문유 형(사실, 추론)은 어떠한 상호적 패턴으로 나타나는지 알아보았다. 이에 대한 예시는 Appendix 1과 같다.

\section{신뢰도}

본 연구에서 양육자의 질문과 아동의 반응에서 나타난 발화 전사 신뢰도와 분석 신뢰도를 검증하기 위하여 검사자 간 일치도를 산출 하였다. 연구자인 제 1 평가자와함께 분석을 진행한 제 2 평가자는 언어 병리학과 석사과정을 수료하였으며, 2 급 언어재활사 자격증을 소지 하고 있다. 본 연구자는 제 2 평가자에게 분석방법과 그 기준에 대하 여 충분히 설명하였으며, 신뢰도를 검증하기 위해 연구대상자의 약 $20 \%$ 에 해당되는 3 명을 임의로 선정하여 책읽기 상황에서 나타난 발 화 자료를 각각 독립적으로 분석하였다. 신뢰도에 대한 산출방법은 연구자와 제 2 평가자 간 일치한 반응을 전체 반응수로 나눈 다음 100 을 곱하여 산출하였으며 그 결과, 전사 신뢰도는 $96.64 \%$ 로 나타났으 며, 분석 신뢰도는 양육자의 질문 $91.72 \%$, 아동의 반응 $92.87 \%$ 였다.

\section{자료의 통계적 처리}

어휘발달지연 아동과 일반아동의 양육자 질문유형(사실, 추론) 과 그에 따른 아동 반응정확도에서 유의미한 차이가 나타나는지 검증하기 위해 이원혼합분산분석(two-way mixed ANOVA)을 실 시하였으며, 사실, 추론질문에 대한 아동의 반응유형(정·오반응)에 따른 양육자의 질문유형(사실, 추론)의 차이를 알아보기 위하여

Table 2. Descriptive statistics of child's accuracy of maternal question types by two groups

\begin{tabular}{lcc}
\hline & \multicolumn{2}{c}{ Child's accuracy (\%) } \\
\cline { 2 - 3 } & VD group ( $\mathrm{N}=17)$ & TD group ( $\mathrm{N}=17)$ \\
\hline Maternal RO & $55.71 \pm 18.78$ & $63.87 \pm 12.60$ \\
Maternal IO & $39.13 \pm 14.38$ & $49.60 \pm 14.09$ \\
\hline
\end{tabular}

Values are presented as mean \pm SD.

$\mathrm{VD}=$ vocabulary delay; $\mathrm{TD}=$ typically developing children; $\mathrm{RQ}=$ referential question; $10=$ inferential question.
맨-휘트니 $U$-검정(Mann-Whitney $U$-test)을 실시하였다. 본 연구 에서 실시한 통계적 분석은 IBM Statistics version 23 (SPSS, Armonk, NY, USA)을 사용하였다

\section{연구결과}

\section{어휘발달지연 아동과 일반아동 집단에서 양육자 질문유형(사실, 추론)에 따른 아동 반응정확도 차이}

어휘발달지연 아동과 일반아동 양육자의 사실질문, 추론질문에 따른 아동의 정반응 비율에 대한 기술통계 결과는 Table 2 와 같다.

두 집단양육자의 질문유형(사실, 추론)에 따른 아동의 반응정확 도 비율에 대한 분산분석 결과는 Table 3 과 같다.

양육자의 사실 및 추론질문에 따른 아동의 정반응률에 대한 기 술통계 결과가 통계적으로 유의한지 검증하기 위하여 이원혼합분 산분석을 실시한 결과, 집단에 대한 주효과가 통계적으로 유의하게 나타났다 $\left(F_{(1,32)}=556.15, p<.05\right)$. 다시 말해, 어휘발달지연 아동 집 단이 일반아동 집단에 비해 양육자의 사실 및 추론질문에 대한 정 반응률이 더 낮게 나타났다. 집단 내 요인으로 양육자의 사실 및 추 론질문에 대한 아동의 정반응률의 주효과가 통계적으로 유의미하 였다 $\left(F_{(1,32)}=30.18, p<.001\right)$. 이는 양육자의 사실질문에 따른 아동 의 정반응률이 양육자의 추론질문에 따른 정반응률보다 유의하게 더 높게 나타났다. 이에 대한 집단 및 질문유형에 따른 정반응률에 대한 상호작용은 통계적으로 유의하게 나타나지 않았다 $\left(F_{(1,32)}=.12\right.$, $p>.05)$. 즉, 양육자의 사실 및 추론질문에 대한 아동의 정반응률에 대한 집단 간 차이가 없었다.

\section{어휘발달지연 아동과 일반아동 집단 간 정반응, 오반응 유형(사실, 추론)에 따른 양육자 질문유형(사실, 추론) 차이} 집단 간 아동의 정반응 유형(사실, 추론)에 따른 양육자

\section{질문유형(사실, 추론) 비율 차이}

어휘발달지연 아동과 일반아동의 사실적 정반응, 추론적 정반 응에 따른 양육자의 사실질문, 추론질문 비율에 대한 기술통계와 맨-휘트니 U-검정 결과는 Table 4 와 같다.

Table 3. Results of two-way mixed ANOVA

\begin{tabular}{llrl}
\hline & \multicolumn{1}{c}{ Predictor } & \multicolumn{1}{c}{$F$} & \multicolumn{1}{c}{$p$-value } \\
\hline Accuracy & TD vs. SLI & 556.15 & $.048^{*}$ \\
& Maternal question types vs. accuracy & 30.18 & $.000^{* * *}$ \\
& Group vs. accuracy of maternal question types & .12 & .734 \\
\hline
\end{tabular}

$\mathrm{TD}=$ typically developing children; $S \mathrm{LI}=$ specific language impairment. ${ }^{*} p<.05,{ }^{* * *} p<.001$. 
위와 같은 기술통계 결과가 통계적으로 유의한지 검증하기 위해 맨-휘트니 U-검정을 실시한 결과, 아동의 사실적 정반응에 따른 양 육자의 사실질문은 일반아동 집단의 중위수 57.14 , 사분위수 범위 28.02 , 어휘발달지연 아동 집단의 중위수 76.47 , 사분위수 범위 20.23 으로 집단 간 비율 차이가 통계적으로 유의한 것으로 나타났다 $(Z=-2.48, p<.01)$. 아동의 사실적 정반응에 따른 양육자의 추론질 문은 일반아동 집단의 중위수 42.86 , 사분위수 범위 14.25 , 어휘발 달지연 아동 집단의 중위수 22.53 , 사분위수 범위 20.23 으로 어휘 발달지연 아동 집단이 유의하게 적은 것으로 나타났다 $(Z=-2.48$, $p<.01)$. 아동의 추론적 정반응에 대한 양육자의 사실질문은 일반 아동 집단의 중위수 50 , 사분위수 범위 44.53 , 어휘발달지연 아동 집단의 중위수 44.44 , 사분위수 범위 43.69 로 유의한 차이가 없었

Table 4. Descriptive maternal question types following by child's correct contributions (referential, inferential)

\begin{tabular}{lccc}
\hline & VD group (N=17) & TD group (N=17) & $Z$ \\
\hline Child's RC & & & \\
Maternal RO & $73.49 \pm 18.20$ & $57.89 \pm 19.48$ & $-2.48^{* *}$ \\
& $(76.47,20.23)$ & $(57.14,28.02)$ & \\
Maternal IO & $26.51 \pm 18.20$ & $42.11 \pm 19.48$ & $-2.48^{* *}$ \\
& $(22.53,20.23)$ & $(42.86,14.25)$ & \\
Child's IC & & & \\
Maternal RO & $43.05 \pm 27.04$ & $56.79 \pm 31.56$ & -1.26 \\
& $(44.44,43.69)$ & $(50.00,44.53)$ & \\
Maternal IO & $56.95 \pm 27.04$ & $43.21 \pm 31.56$ & -1.26 \\
& $(55.56,43.69)$ & $(50.00,44.54)$ & \\
\hline
\end{tabular}

Values are presented as mean \pm SD (median, quartile).

$\mathrm{VD}=$ vocabulary delay; $\mathrm{TD}=$ typically developing children; $\mathrm{RC}=$ referential correctness; $\mathrm{IC}=$ inferential correctness; $\mathrm{R} 0=$ referential question; $\mathrm{IQ}=$ inferential question . ${ }^{*} p<.05,{ }^{* *} p<.01$.

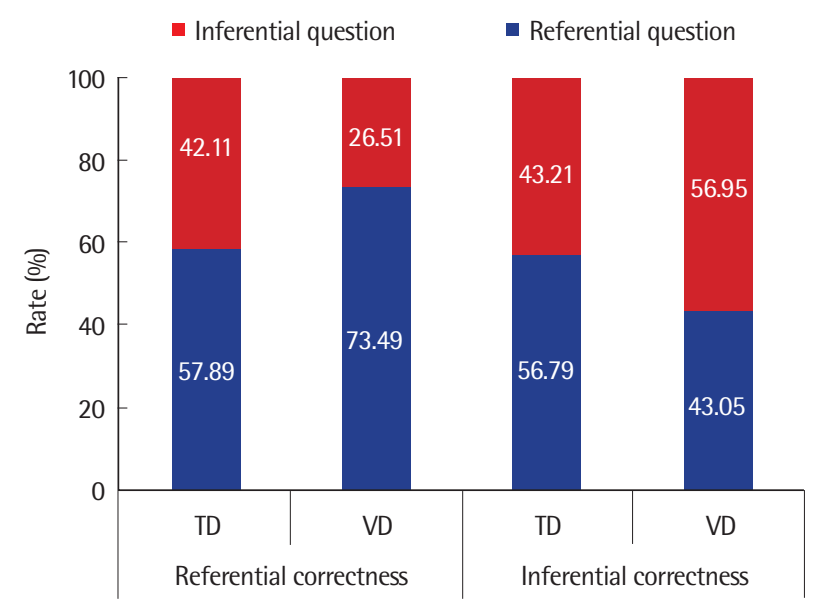

Figure 1. Maternal question types by child's correctness types of two groups. $\mathrm{VD}=$ vocabulary delay; $\mathrm{TD}=$ typically developing children .
다 $(Z=-1.26, p>.05)$. 아동의 추론적 정반응에 대한 양육자의 추론 질문은 일반아동 집단의 중위수는 50 , 사분위수 범위는 44.54 , 어 휘발달지연 아동 집단의 중위수 55.56 , 사분위수 범위 43.69 로 집 단 간 유의한차이가 없었다 $(Z=-1.26, p>.05)$. 두 집단의 아동 정반 응 유형(사실, 추론)에 따른 양육자 질문유형(사실, 추론)에 대한 그래프를 Figure 1에 제시하였다.

\section{집단 간 아동의 오반응 유형(사실, 추론)에 따른 양육자}

\section{질문유형(사실, 추론) 비율 차이}

어휘발달지연 아동과 일반아동의 사실적 오반응, 추론적 오반 응에 따른 양육자의 사실질문, 추론질문 비율에 대한 기술통계 결 과와 맨-휘트니 U-검정 결과는 Table 5 와 같다.

위와 같은 기술통계 결과가 통계적으로 유의한지 알아보기 위해 맨-휘트니 U-검정을 실시한 결과, 아동의 사실적 오반응에 따른 양 육자의 사실질문은 일반아동 집단의 중위수 75 , 사분위수 범위 32.3 , 어휘발달지연 아동 집단의 중위수 71.43 , 사분위수 범위 36.83 으로 집단 간 유의한 차이가 없었다 $(Z=-1.21, p>.05)$. 아동의 사실 적 오반응에 따른 양육자의 추론질문은 일반아동 집단의 중위수 25 , 사분위수 범위 32.3 , 어휘발달지연 아동 집단의 중위수 28.57 , 사분위수 범위 36.82 로 유의한 차이가 없었다 $(Z=-1.21, p>.05)$. 아 동의 추론적 오반응에 대한 양육자의 사실질문은 일반아동 집단 의 중위수 71.43 , 사분위수 범위 15 , 어휘발달지연 아동 집단의 중 위수 41.67 , 사분위수 범위 29.73으로 어휘발달지연 아동 집단이 유 의하게 적은 것으로 나타났다 $(Z=-4.26, p<.001)$. 아동의 추론적 오반응에 대한 양육자의 추론질문은 일반아동 집단의 중위수 28.57 , 사분위수 범위 14.99 , 어휘발달지연 아동 집단의 중위수 58.33 , 사

Table 5. Descriptive maternal question types following by child's incorrect contributions (referential, inferential)

\begin{tabular}{lccc}
\hline & VD group (N=17) & TD group (N=17) & $Z$ \\
\hline Child's RI & & & \\
Maternal R0 & $71.71 \pm 20.71$ & $68.59 \pm 2.183$ & -.121 \\
& $(71.43,36.83)$ & $(75.00,32.30)$ & \\
Maternal IO & $28.29 \pm 20.71$ & $31.41 \pm 21.83$ & -.121 \\
& $(28.57,36.82)$ & $(25.00,32.30)$ & \\
Child's II & & & \\
Maternal R0 & $38.02 \pm 22.17$ & $71.10 \pm 15.73$ & $-4.26^{* * *}$ \\
& $(41.67,29.73)$ & $(71.43,15.00)$ & \\
Maternal IO & $61.98 \pm 22.17$ & $28.90 \pm 15.73$ & $-4.26^{* * *}$ \\
& $(58.33,29.74)$ & $(28.57,14.99)$ & \\
\hline
\end{tabular}

Values are presented as mean $\pm \mathrm{SD}$ (median, quartile).

$\mathrm{VD}=$ vocabulary delay; $\mathrm{TD}=$ typically developing children; $\mathrm{RI}=$ referential incorrectness; $\|$ = inferential incorrectness; $\mathrm{RQ}=$ referential question; $\mathrm{IQ}=$ inferential question. ${ }^{*} p<.05,{ }^{* * *} p<.001$. 


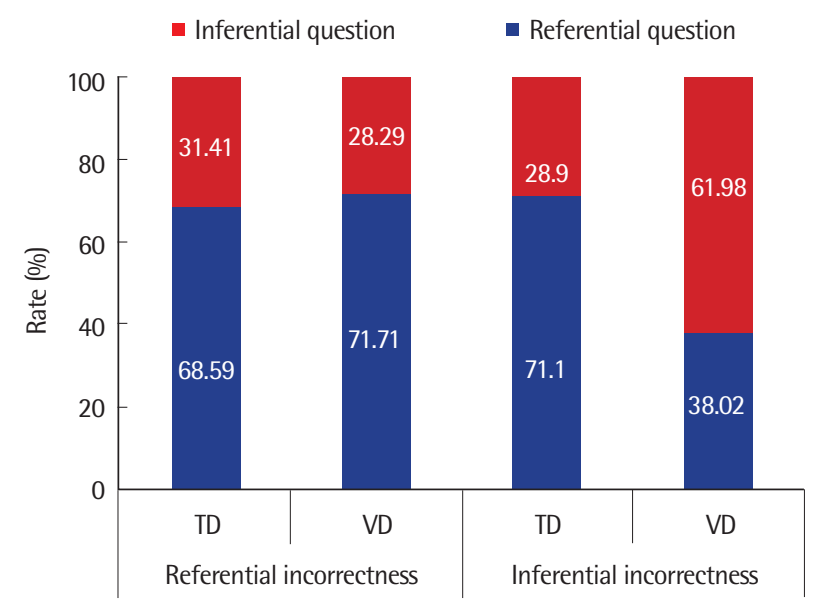

Figure 2. Maternal question types by child's incorrectness types of two groups. $\mathrm{VD}=$ vocabulary delay; $\mathrm{TD}=$ typically developing children .

분위수 범위 29.74로 집단 간 비율 차이가 통계적으로 유의한 것으 로 나타났다 $(Z=-4.26, p<.001)$. 두 집단의 아동 오반응 유형(사실, 추론)에 따른 양육자 질문유형(사실, 추론)에 대한 그래프를 Figure 2에 제시하였다.

\section{논의 및 결론}

양육자-아동 책읽기 동안 나타나는 양육자의 질문은 질적으로 높은 행동으로 평가된다(Crain-Thoreson \& Dale, 1999; Whitehurst et al., 1988). 다수의 선행연구에서는 양육자의 질문이 아동의 반응에 미치는 영향에 대해 살펴보았다. 그러나 양육자의 질문에 대한 아동의 반응에 따르는 후속반응으로서 양육자의 질문에 대 한 연구는 부족한 실정이다. 실제로 책읽기 동안 양육자의 질문만 이 아동의 참여를 이끌어내는 것이 아니라 아동의 적극적인 참여 또한 양육자의 질문을 유도할 수 있다. 이때, 양육자의 질문의 인지 적 수준에 따라 아동의 반응이 다르게 나타나며 서로 다르게 나타 난 아동의 반응에 따라 나오는 양육자의 질문의 인지적 수준도 달 라지기 때문에 두 가지 요소의 상호작용이 중요하다. 선행연구에서 양육자는 아동의 언어 능력에 기초하여 인지적 요구 난이도를 조 절함을 밝혔다(Pellegrini et al., 1985). 예를 들면, 아동이 틀린 대답 을 했을 때 양육자는 인지수준이 더 낮은 질문을 이어서 할 수도 있 지만, 아동이 정확하게 대답했을 때에는 더 높은 인지수준을 요구 하는 질문으로 바꿀 수도 있다. 따라서 본 연구에서는 책을 읽는 동 안 나타난 양육자의 질문유형이 아동의 반응에 어떻게 영향을 미 쳤고, 반대로 아동의 반응이 양육자의 질문에는 어떠한 영향을 주 는지 동시에 살펴보고자 하였다.
본 연구에서는 양육자-아동 책읽기 시 일반 아동과 어휘발달지 연 아동의 양육자 질문과 아동의 구어 반응이 어떠한 상호적 패턴 으로 나타나는지 알아보기 위해 만 4-6세 아동을 대상으로 (1) 일 반아동과 어휘발달지연 아동 집단에서 양육자의 질문유형(사실, 추론)에 따른 아동의 반응정확도 차이가 유의한지, (2) 아동이 정 반응, 오반응을 보인 유형(사실, 추론)에 따른 양육자의 질문유형 (사실, 추론)에서 유의한 차이를 보이는지 알아보고자 하였다.

먼저, 만 4-6세 어휘발달지연 아동 집단과 일반아동 집단에서 양 육자의 사실, 추론질문에 대한 아동의 반응정확도에 대한 차이를 비교해 보았다. 두 집단 간 비교한 결과, 양육자의 사실 및 추론질문 에 따른 아동의 정반응에 대한 2 차 상호작용이 유의하지 않았다. 그러나 집단 간 주효과를 비교해본 결과, 일반아동 집단에서 양육 자의 사실질문 및 추론질문에 대한 아동의 정반응률이 어휘발달 지연 아동 집단보다 통계적으로 유의하게 높았다. 또한, 양육자의 사실질문에 따른 정반응률이 추론질문에 따른 정반응률보다 유의 하게 높았다.

따라서 아동들이 사실질문보다 추론질문을 더 어려워한다는 선 행연구(Bishop \& Adams, 1992; Hammett et al., 2003; Lee, Kinzie, \& Whittaker, 2012; McGinty, Justice, Zucker, Gosse, \& Skibbe, 2012) 를 뒷받침하며, 어휘발달지연 아동은 양육자의 질문에 대한 틀린 답을 산출하는 정도가 높다고 밝힌 선행연구(Barachetti \& Lavelli, 2011; Yont, Hewitt, \& Miccio, 2000)와 일치하였다.

본 연구는 책읽기 상황에서 양육자의 질문에 따른 아동의 반응 을 살펴봄으로써, 양육자가 아동에게 미치는 영향에 대해 살펴보 았다. 본 연구의 대상은 학령전기 4-6세 아동임을 고려하였을 때, 양육자의 사실질문은 만 4,5 세경의 학령전기 아동에서 이야기 내 용의 기본적인 요소와 구성에 대해 이끌어내는 역할을 한다. 이러 한 질문은 추론질문보다 낮은 인지적 수준을 요구하지만 아동의 언어습득을 향상시키는 데 중요한 역할을 한다. 하지만 양육자의 추론질문은 아동의 이야기 구성에 대한 이해의 폭을 증가시켜 서 술적 참여에 중요한 역할을 할 수 있다는 선행연구(Kuchirko, Tamis-LeMonda, Luo, \& Liang, 2016)의 주장에 따라 임상에서 아동 의 상호작용적 책읽기 시 인지적 수준을 달리 요구하는 질문의 유 형을 다양화할 필요성이 있다.

다음으로, 본 연구에서는 양육자-아동 상호작용적 책읽기 상황 에서 어휘발달지연 아동 집단과 일반아동 집단 간 아동의 정반응 및 오반응 유형(사실, 추론)에 대한 양육자의 사실질문 및 추론질 문의 차이를 비교해 보았다.

그 결과 어휘발달지연 아동 집단에서 아동의 사실적 정반응에 대해 양육자의 사실질문 비율이 일반아동 집단보다 유의하게 높았 
다. 이는 책읽기 상황에서 아동이 양육자와의 대화에 참여하기 시 작하면 양육자는 아동의 반응과 동일한 인지수준의 질문을 유지 한다는 선행연구 결과와 일치하였으며(Luo \& Tamis-LeMonda, 2017), 언어에 어려움이 나타나는 아동은 낮은 인지적 수준을 요구 하는 질문에 따른 어휘 습득력이 높을 것이라는 선행연구를 뒷받 침한다(Reese \& Cox, 1999). 또한, 어휘발달지연 아동 집단에서 아 동의 추론적 오반응에 따른 양육자의 추론질문이 일반아동 집단 에 비해 유의하게 높은 것으로 나타났다. 그러나 아동의 추론적 정 반응에 따른 양육자의 사실질문뿐만 아니라 추론질문에서는 두 집단 간 유의미한 차이가 없었다. 이는 아동이 오반응을 보인 경우 낮은 인지수준을 요구하는 양육자의 질문이 이어서 나온다는 선행 연구 결과(Luo \& Tamis-LeMonda, 2017; Ninio, 1983)와는 반대로 나타났으며, 어휘발달지연 아동 양육자는 아동이 보인 오반응에 대해 오히려 더 어려운 질문을 한 것으로 나타났다. 본 연구와 같이 선정된 책에 대한 친숙도가 낮은 경우에는 양육자 질문의 인지적 수준에 관계없이 사실 및 추론질문 모두 아동의 언어습득에 긍정 적인 영향을 준다는 선행연구 결과(Justice, 2002)를 뒷받침한다. 또 한, 양육자의 추론질문은 아동의 이해능력을 향상시켜주어 아동 의 연령이 증가할수록 더 성숙한 읽기 학습자로 거듭날 수 있게 하 며(Palinscar \& Brown, 1984; Van Kleeck et al., 2006), 아동의 어휘 와 인지발달에 매우 긍정적이고 중요한 예측 요인이 될 수 있으므 로(de Rivera et al., 2005; Dickinson \& Porche, 2011; Hindman \& Wasik, 2008; Lee \& Kinzie, 2012), 본 연구의 결과에서처럼 양육자 가 아동에게 추론질문을 많이 할수록 아동의 언어발달에 도움을 줄수 있을 것이라 예상된다.

한편 일반아동 집단에서는 아동의 사실적 정반응에 대해 양육 자가 추론질문을 하는 비율이 유의하게 높게 나타났다. 그러나 아 동의 사실적 오반응에 대한 양육자의 사실질문 및 추론질문에서 는 두 집단 간 유의미한 차이가 나타나지 않았다. 또한, 일반아동 집 단에서 아동의 추론적 오반응에 대해 양육자의 사실질문 비율이 유의하게 높게 나타났다. 이는 아동이 정반응을 보이면 양육자는 인지적으로 더 높은 수준의 질문을 하고, 반대로 오반응을 보이면 양육자는 인지적으로 더 낮은수준의 질문을 한다는 선행연구(Ninio, 1983)와 일치하였다. 즉, 양육자는 아동의 정반응 또는 오반응과 같 은 반응정확도에 따라 다른 유형의 질문으로 옮겨갈 수 있음을 밝 힌 선행연구 결과(Danis et al., 2000; Kuchirko et al., 2016; Wood, \& Middleton, 1975)와 동일함을 확인할 수 있었다.

본 연구는 양육자-아동의 상호작용적 책읽기 상황에서 양육자 가 아동에게 미치는 영향뿐만 아니라 아동이 양육자에게 미치는 영향을 동시에 살펴보고자 하였다. 즉, 아동 반응유형과 정확도에
따라 변화하는 양육자의 질문유형을 살펴보았으며 집단 간 유의미 한 차이가 있었던 것을 확인함으로써 양육자가 아동의 언어 및 인 지적 수준에 따라 적절한 질문을 제공할 필요성이 있을 것으로 예 상된다. 그러나 이를 명확하게 뒷받침할 수 있으려면 본 연구의 분 석에 포함한 부분을 이은 양육자의 질문유형에 따른 아동의 반응 유형 및 정확도를 한번 더 살펴볼 필요성이 제기된다. 또한, 아동의 연령이 증가함에 따라 높은 인지적 수준을 요구하는 질문의 빈도 수가 높아지는 점을 고려하여(Van Kleeck \& Beckley-McCall, 2002) 후속연구에서 학령기 아동과 양육자의 상호작용적 책읽기 에서 나타나는 반응과 질문의 상호관계를 살펴본다면 보다 정교한 아동의 문해능력 발달을 증진시킬 수 있는 지표가 될 수 있을 것으 로보인다.

본 연구에서는 책읽기 상황 안에서의 양육자 질문과 아동 반응 을 살펴봄과 동시에 두 양육자 집단 간 책읽기 방식에서는 차이가 나지 않음을 증명하기 위해 양육자의 발화에 대한 MLC-w를 분석 하였다. 그럼에도 불구하고 아동의 반응에 대한 양육자의 질문만 분석하여 일반화시킨 것에 한계가 있다. 양육자는 아동 반응에 대 해 확장, 모방, 수정, 재구성과 같은 코멘트를 해줄 수 있으며 이 또한 아동의 언어발달에 도움을 준다고 밝힌 선행연구(Harris \& Schroeder, 2012)를 토대로 질문을 제외한 양육자의 다양한 코멘트에 대 한 분석이 필요할 것으로 보인다.

\section{REFERENCES}

Adams, C. (1990). Syntactic comprehension in children with expressive language impairment. British Journal of Disorders of Communication, 25, 149171.

Arnold, D. H., Lonigan, C. J., Whitehurst, G. J., \& Epstein, J. N. (1994). Accelerating language development through picture book reading: replication and extension to a videotape training format. Journal of Educational Psychology, 86, 235-243.

Asch, F. (1983). Mooncake. New York, NY: Aladdin.

Asch, F. (1985). Bear Shadow. New York, NY: Aladdin.

Barachetti, C., \& Lavelli, M. (2011). Responsiveness of children with specific language impairment and maternal repairs during shared book reading. International Journal of Language \& Communication Disorders, 46, 579591.

Bishop, D. V., \& Adams, C. (1992). Comprehension problems in children with specific language impairment: literal and inferential meaning. Journal of Speech, Language, and Hearing Research, 35, 119-129. 
Blank, M., Rose, S. A., \& Berlin, L. J. (1978). The language of learning: the preschool years. New York, NY: Grune \& Stratton.

Bornstein, M. H., \& Tamis-LeMonda, C. S. (1989). Maternal responsiveness and cognitive development in children. New Directions for Child and Adolescent Development, 1989, 49-61.

Bus, A. G. (2003). Social-emotional requisites for learning to read. In On reading books to children (pp. 17-28). Mahwah, NJ: Erlbaum Associates.

Bus, A. G., Belsky, J., Van Ijzendoom, M. H., \& Crnic, K. (1997). Attachment and bookreading patterns: a study of mothers, fathers, and their toddlers. Early Childhood Research Quarterly, 12, 81-98.

Bus, A. G., Van Ijzendoorn, M. H., \& Pellegrini, A. D. (1995). Joint book reading makes for success in learning to read: a meta-analysis on intergenerational transmission of literacy. Review of Educational Research, 65, 1-21.

Chall, J. S. (1983). Stages of reading development. New York, NY: McGrawHill.

Chapman, R. S. (2000). Children's language learning: an interactionist perspective. The Journal of Child Psychology and Psychiatry and Allied Disciplines, 41, 33-54.

Clark, E. V. (1995). Later lexical development and word formation. In P. Fletcher \& B. MacWhinney (Eds.), The handbook of child language (pp. 393-412). Cambridge, MA: Blackwell.

Cochran-Smith, M. (1984). The making of a reader. Norwood, NJ: Ablex Publishing Corp.

Crain-Thoreson, C., \& Dale, P. S. (1992). Do early talkers become early readers? Linguistic precocity, preschool language, and emergent literacy. Developmental Psychology, 28, 421-429.

Crain-Thoreson, C., \& Dale, P. S. (1999). Enhancing linguistic performance: parents and teachers as book reading partners for children with language delays. Topics in Early Childhood Special Education, 19, 28-39.

Danis, A., Bernard, J. M., \& Leproux, C. (2000). Shared picture-book reading: a sequential analysis of adult-child verbal interactions. British Journal of Developmental Psychology, 18, 369-388.

DeLoache, J. S., \& DeMendoza, O. A. (1987). Joint picturebook interactions of mothers and 1-year-old children. British Journal of Developmental Psychology, 5, 111-123.

De Rivera, C., Girolametto, L., Greenberg, J., \& Weitzman, E. (2005). Children's responses to educators' questions in day care play groups. American Journal of Speech-Language Pathology, 14, 14-26.

Dickinson, D. K., \& Porche, M. V. (2011). Relation between language experiences in preschool classrooms and children's kindergarten and fourth-grade language and reading abilities. Child Development, 82, 870-886.

Dickinson, D. K., \& Snow, C. E. (1987). Interrelationships among prereading and oral language skills in kindergartners from two social classes. Early Childhood Research Quarterly, 2, 1-25.

Girolametto, L., Weitzman, E., \& Greenberg, J. (2003). Training day care staff to facilitate children's language. American Journal of Speech-Language Pathology, 12, 299-311.

Hammett, L. A., Kleeck, A., \& Huberty, C. J. (2003). Patterns of parents' extratextual interactions during book sharing with preschool children: a cluster analysis study. Reading Research Quarterly, 38, 442-468.

Han, M. K., Seong, S. Y., \& Choi, S. J. (2016). Words in storybooks as children's language input environment: predicates. Communication Sciences \& Disorders, 21, 98-110.

Harris, Y. R., \& Schroeder, V. M. (2012). What the Berenstain Bears can tell us about school readiness: maternal story grammar style and preschool narrative recall. Journal of Early Childhood Research, 10, 176-195.

Hindman, A. H., \& Wasik, B. A. (2008). Head Start teachers' beliefs about language and literacy instruction. Early Childhood Research Quarterly, 23, 479-492.

Hindman, A. H., Wasik, B. A., \& Erhart, A. C. (2012). Shared book reading and Head Start preschoolers' vocabulary learning: the role of book-related discussion and curricular connections. Early Education \& Development, $23,451-474$.

Justice, L. M. (2002). Word exposure conditions and preschoolers' novel word learning during shared storybook reading. Reading Psychology, 23, 87-106. Justice, L. M., \& Kaderavek, J. (2002). Using shared storybook reading to promote emergent literacy. Teaching Exceptional Children, 34, 8-13.

Kang, Y. H., \& Hong, G. H. (2016). The effects of 'dialogic reading' on story retelling of children with language disabilities at ages 6 and 7. Communication Sciences \& Disorders, 21, 84-97.

Karrass, J., \& Braungart-Rieker, J. M. (2005). Effects of shared parent-infant book reading on early language acquisition. Journal of Applied Developmental Psychology, 26, 133-148.

Kim, S. (2010). The relationship between the parents' socioeconomic status and the English academic achievement of the second grade students of high school (Master's thesis). Yonsei University, Seoul, Korea.

Kim, Y. T., Hong, G. H., Kim, K. H., Jang, H. S., \& Lee, J. Y. (2009). Receptive \& expressive vocabulary test (REVT). Seoul: Seoul Community Rehabilitation Center.

Kuchirko, Y., Tamis-LeMonda, C. S., Luo, R., \& Liang, E. (2016). 'What hap- 
pened next?': developmental changes in mothers' questions to children. Journal of Early Childhood Literacy, 16, 498-521.

Lee, Y., \& Kinzie, M. B. (2012). Teacher question and student response with regard to cognition and language use. Instructional Science, 40, 857-874.

Lee, Y., Kinzie, M. B., \& Whittaker, J. V. (2012). Impact of online support for teachers' open-ended questioning in pre-k science activities. Teaching and Teacher Education, 28, 568-577.

Lonigan, C. J. (1994). Reading to preschoolers exposed: is the emperor really naked? Developmental Review, 14, 303-323.

Luo, R., \& Tamis-LeMonda, C. S. (2017). Reciprocity between maternal questions and child contributions during book-sharing. Early Childhood Research Quarterly, 38, 71-83.

Mandel Morrow, L. (1983). Home and school correlates of early interest in literature. The Journal of Educational Research, 76, 221-230.

Massey, S. L., Pence, K. L., Justice, L. M., \& Bowles, R. P. (2008). Educators' use of cognitively challenging questions in economically disadvantaged preschool classroom contexts. Early Education and Development, 19, 340360.

McGinty, A. S., Justice, L. M., Zucker, T. A., Gosse, C., \& Skibbe, L. E. (2012). Shared-reading dynamics: mothers' question use and the verbal participation of children with specific language impairment. Journal of Speech, Language, and Hearing Research, 55, 1039-1052.

Melzi, G., Schick, A. R., \& Kennedy, J. L. (2011). Narrative elaboration and participation: two dimensions of maternal elicitation style. Child Development, 82, 1282-1296.

Montag, J. L., Jones, M. N., \& Smith, L. B. (2015). The words children hear: picture books and the statistics for language learning. Psychological Science, 26, 1489-1496.

Moon, S. B., \& Byun, C. J. (2003). Korean Kaufman assessment battery for children $(K-A B C)$. Seoul: Hakjisa.

Ninio, A. (1983). Joint book reading as a multiple vocabulary acquisition device. Developmental Psychology, 19, 445.

Norbury, C. F., \& Bishop, D. V. (2002). Inferential processing and story recall in children with communication problems: a comparison of specific language impairment, pragmatic language impairment and high-functioning autism. International Journal of Language \& Communication Disorders, 37, 227-251.

Oh, Y. S., Kim, J. M., \& Lee, S. H. (2008). The effect of dialogic reading program for parents of children with developmental language delays. Korean Journal of Early Childhood Special Education, 8, 139-154.
Owens, J. (2010). What is a Language?: Review of Bernard Comrie, Ray Fabri, Elizabeth Hume, Manwel Mifsud, Thomas Stolz \& Martine Vanhove (eds.), Introducing Maltese Linguistics. Selected papers from the 1st International Conference on Maltese Linguistics, Bremen, 18-20 October. 2007, 2009. XI, 422 pages. Studies in Language Companion Series 113. Amsterdam-Philadelphia: John Benjamins. Journal of Language Contact, 3, 103118.

Pae, S., Kwon, E. G., Jin, Y. S., Jun, H. J., \& Kwak, K. J. (2010). Narratives of children with multicultural backgrounds. Journal of Speech \& Hearing Disorders, 19, 53-72.

Palinscar, A. S., \& Brown, A. L. (1984). Reciprocal teaching of comprehension-fostering and comprehension-monitoring activities. Cognition and Instruction, 1, 117-175.

Pellegrini, A. D., Brody, G. H., \& Sigel, I. E. (1985). Parents' book-reading habits with their children. Journal of Educational Psychology, 77, 332-340.

Rabidoux, P. C., \& MacDonald, J. D. (2000). An interactive taxonomy of mothers and children during storybook interactions. American Journal of Speech-Language Pathology, 9, 331-344.

Reese, E., \& Cox, A. (1999). Quality of adult book reading affects children's emergent literacy. Developmental Psychology, 35, 20-28.

Reese, E., \& Newcombe, R. (2007). Training mothers in elaborative reminiscing enhances children's autobiographical memory and narrative. Child Development, 78, 1153-1170.

Scarborough, H. S., \& Dobrich, W. (1994). Another look at parent-preschooler bookreading: how naked is the emperor?: a response to Lonigan (1994) and Dunning, Mason, and Stewart (1994). Developmental Review, 14, 340347.

Sénéchal, M., LeFevre, J. A., Hudson, E., \& Lawson, E. P. (1996). Knowledge of storybooks as a predictor of young children's vocabulary. Journal of Educational Psychology, 88, 520-536.

Sénéchal, M., Thomas, E., \& Monker, J. A. (1995). Individual differences in 4-year-old children's acquisition of vocabulary during storybook reading. Journal of Educational Psychology, 87, 218-229.

Snow, C. (1983). Literacy and language: relationships during the preschool years. Harvard Educational Review, 53, 165-189.

Snow, C. E., Burns, M. S., \& Griffin, P. (1998). Preventing reading difficulties in young children committee on the prevention of reading difficulties in young children. Washington, DC: National Research Council.

Van Kleeck, A., \& Beckley-McCall, A. (2002). A comparison of mothers' individual and simultaneous book sharing with preschool siblings: an ex- 
ploratory study of five families. American Journal of Speech-Language Pathology, 11, 175-189.

Van Kleeck, A., Vander Woude, J., \& Hammett, L. (2006). Fostering literal and inferential language skills in Head Start preschoolers with language impairment using scripted book-sharing discussions. American Journal of Speech-Language Pathology, 15, 85-95.

Walsh, B. A., \& Blewitt, P. (2006). The effect of questioning style during storybook reading on novel vocabulary acquisition of preschoolers. Early Childhood Education Journal, 33, 273-278.

Wheeler, A., Hatton, D., Reichardt, A., \& Bailey, D. (2007). Correlates of maternal behaviours in mothers of children with fragile X syndrome. Journal of Intellectual Disability Research, 51, 447-462.

Whitehurst, G. J., Falco, F. L., Lonigan, C. J., Fischel, J. E., DeBaryshe, B. D., Valdez-Menchaca, M. C., \& Caulfield, M. (1988). Accelerating language development through picture book reading. Developmental Psychology, 24, 552-559.
Wood, D., \& Middleton, D. (1975). A study of assisted problem-solving. British Journal of Psychology, 66, 181-191.

Yim, D., Cheon, S. H., Lee, Y. J., \& Jeong, P. Y. (2015). Meta analysis of spontaneous speech between children with language developmental disorders and typical developing children: a preliminary study for developing an application screening tool. Journal of Speech \& Hearing Disorders, 24, 57-75.

Yoder, P. J., \& Warren, S. F. (1999). Maternal responsivity mediates the relationship between prelinguistic intentional communication and later language. Journal of Early Intervention, 22, 126-136.

Yont, K. M., Hewitt, L. E., \& Miccio, A. W. (2000). A coding system for describing conversational breakdowns in preschool children. American Journal of Speech-Language Pathology, 9, 300-309.

Zucker, T. A., Cabell, S. Q., Justice, L. M., Pentimonti, J. M., \& Kaderavek, J. N. (2013). The role of frequent, interactive prekindergarten shared reading in the longitudinal development of language and literacy skills. Developmental Psychology, 49, 1425-1439. 
Appendix 1. 두 집단 양육자의 질문유형 및 아동 반응 유형

\begin{tabular}{|c|c|}
\hline 일반아동 & 어휘발달지연 아동 \\
\hline 사실질문 $\rightarrow$ 사실적 반응 & 사실질문 $\rightarrow$ 사실적 반응 \\
\hline $\begin{array}{l}\text { - 달곰이가 뭐 먹고 싶었어? } \rightarrow \text { 달케이크(정) } \\
\text { - 달곰이랑 작은 새는 뭘 만들었지? } \rightarrow \text { 우주선 만들었어(정) } \\
\text { - 숟가락이 달까지 날아갔어? } \rightarrow \text { 응(오) } \\
\text { - 누가 깨어났어 } ? \rightarrow \text { 달곰이(정) } \\
\text { - 달케이크 맛은 어땠어? } \rightarrow \text { 끔찍했어(오) } \\
\text { - 달곰이가 지금 뭐해? } \rightarrow \text { 망치로 뚝딱해(정) } \\
\text { - 달곰이가 그림자한테 뭐라고 했어? } \rightarrow \text { 저리가 }(\text { 오) } \\
\text { - 그림자가 어디로 갔어 } ? \rightarrow \text { 나무 뒤에 숨었어(정) }\end{array}$ & $\begin{array}{l}\text { - 여기에 누가 나오지? } \rightarrow \text { 달곰이랑 새(정) } \\
\text { - 화살을 달로 쐈는데 성공했어 실패했어? } \rightarrow \text { 성공했어(오) } \\
\text { - 달곰이가 우주선 안에서 뭐했어? } \rightarrow \text { 숫자 셌어(정) } \\
\text { - 달곰이가 진짜 케이크 먹었어? } \rightarrow \text { 응(오) } \\
\text { - 달곰이가 화살에 뭐 붙여서 달에 쐈어? } \rightarrow \text { 숟가락(정) } \\
\text { - 달곰이가 낚시해서 뭐 잡았어? } \rightarrow \text { 가재 }(\text { 오) }\end{array}$ \\
\hline 추론질문 $\rightarrow$ 추론적 반응 & 추론질문 $\rightarrow$ 추론적 반응 \\
\hline $\begin{array}{l}\text { - 숟가락을 왜 달에 쏘았을까? } \rightarrow \text { 케이크 먹으려고(정) } \\
\text { - 새가 떠날 때 달곰이의 기분은 어땠을까? } \rightarrow \text { 기뻤어(오) } \\
\text { - 우주선이 뭐야? } \rightarrow \text { 하늘 높이 날아가는 거야(정) } \\
\text { - 낚시 할 때 지렁이가 왜 필요할까? } \rightarrow \text { 물고기를 잡아야 하니까(정) } \\
\text { - 계속 그림자가 생겨서 달곰이 기분이 어땠을까? } \rightarrow \text { 신나(오) } \\
\text { - 달곰이가 자는 동안 해가 어떻게 될까? } \rightarrow \text { 해가 다시 나와(정) }\end{array}$ & $\begin{array}{l}\text { - 그림자가 왜 자꾸 달곰이를 쫓아올까? } \rightarrow \text { 몰라(오) } \\
\text { - 해님이랑 그림자는 항상 같이 있어? } \rightarrow \text { 응(오) } \\
\text { - 달은 무슨 모양일까? } \rightarrow \text { 네모(오) } \\
\text { - 해가 높이 있을 때는 왜 그림자가 없을까? -높으니까(오) } \\
\text { - 호수가 뭐야? } \rightarrow \text { 큰 물이야(정) } \\
\text { - 그림자를 땅에 묻으려면 어떻게 해야 할까? } \rightarrow \text { 삽으로 흙을 파(정) }\end{array}$ \\
\hline
\end{tabular}




\section{국문초록}

\section{상호작용적 책읽기 상황에서 양육자의 질문유형에 따른 어휘발달지연 아동의 정·오반응 비교 연구 이상언 · 임동선 \\ 이화여자대학교 일반대학원 언어병리학과}

배경 및 목적: 책읽기 시에 나타나는 양육자-아동 간의 언어적 상호작용은 아동의 언어 및 문해 발달에 중요한 요소라고 할 수 있다. 따 라서 양육자의 질문유형과 어휘발달지연 아동의 반응 관계를 알아보고자 한다. 방법: 본 연구에 참여한 아동은 만 4-6세의 어휘발달지 연 아동과 양육자 17 쌍, 그리고 이들과 생활연령이 일치하는 일반아동과 양육자 17 쌍이었다. 양육자의 질문과 아동 반응의 관계를 분 석하기 위해 양육자가 아동에게 책 2 권을 읽어주고 질문하는 상황을 녹화하였다. 결과: 일반아동 집단에서 양육자의 사실질문 및 추론 질문에 대한 아동의 정반응률이 어휘발달지연 아동 집단보다 통계적으로 유의하게 높게 나타났다. 어휘발달지연 아동 집단에서 아동 의 사실적 정반응에 대한 양육자의 사실질문 비율과 아동의 추론적 오반응에 따른 양육자의 추론질문이 일반아동 집단에 비해 유의 하게 높은 것으로 나타났다. 일반아동 집단에서 아동의 사실적 정반응에 대한 양육자의 추론질문 비율과 아동의 추론적 오반응에 대 한 양육자의 사실질문 비율이 어휘발달지연 아동 집단에 비해 유의하게 높게 나타났다. 논의 및 결론: 양육자-아동 책읽기 시 양육자 와아동이 서로에게 언어적 영향을 미칠 수 있으며, 양육자 질문의 유형을 다양화하고, 양육자가 아동의 연령, 언어 및 인지수준에 따라 적절한 질문을 제공할 필요성을 확인한 점에서 본 연구는 임상적 의의가 있다.

핵심어: 어휘발달지연 아동, 양육자-아동 책읽기 상호작용, 양육자 사실질문, 양육자 추론질문

본 논문은 2018년도 정부(교육부)의 재원으로 한국연구재단의 지원을 받아 수행된 기초연구사업임(NRF-2016R1D1A1B03935703).

\section{참고문헌}

강영희, 홍경훈(2016). 6-7세 언어발달지체 아동의 이야기에 대한 ‘대화식 책 읽기' 효과. 언어청각장애연구, 21, 84-97

김수영(2010). 부모의 사회경제적 지위와 고등학생의 영어 학업성취도 간 상관관계에 관한 연구. 연세대학교 대학원 석사학위논문.

김영태, 홍경훈, 김경희, 장혜성, 이주연(2009). 수용·표현어휘력검사(REVT). 서울: 서울장애인종합복지관.

문수백, 변창진(2003). K-ABC 교육· 심리측정도구(Korean-Kaufman assessment battery for children). 서울: 학지사.

배소영, 권유진, 진연선, 전홍주, 곽금주(2010). 다문화가정 아동의 이야기 산출. 언어치료연구, 19, 53-72.

오영신, 김정미, 이수향(2008). 대화식 책읽기 부모교육 프로그램이 언어발달지체아동의 발화와 부모의 행동에 미치는 효과. 유아특수교육연구, 8, 139-154.

임동선, 천성혜, 이여진, 정필연(2015). 메타 분석을 통한 언어발달장애 아동과 일반 아동의 자발화 분석 연구. 언어치료연구, 24, 57-75.

한민경, 성시연, 최서진(2016). 아동의 어휘발달 촉진을 위한 언어입력환경으로서의 동화책 어휘 연구: 용언을 중심으로. 언어청각장애연구, 21, 98-

110. 